\title{
TRANSFORMATION OF STRUCTURAL DEFECTS AND THE HYDROGEN STATE UPON HEAT TREATMENT OF HYDROGENATED SILICON
}

\author{
Yu. M. Pokotilo, ${ }^{a *}$ A. M. Petuh, ${ }^{a}$ O. Yu. Smirnova, ${ }^{a}$ \\ G. F. Stelmakh, ${ }^{\text {VV. P. Markevich, }}{ }^{\text {O O. V. Korolik, }},{ }^{\text {a }}$ \\ I. A. Svito, ${ }^{a}$ and A. M. Saad ${ }^{\mathrm{c}}$
}

Transformations of structural defects, the hydrogen state, and electrophysical properties of silicon treated in hydrogen plasma are studied. Treatment in plasma $\left(150^{\circ} \mathrm{C}\right)$ produces bands in Raman spectra at 2095 and $2129 \mathrm{~cm}^{-1}$ that are associated with scattering by Si-H vibrations. Subsequent heat treatment (275 $\left.{ }^{\circ} \mathrm{C}\right) \mathrm{causes}$ a band for gaseous molecular $\mathrm{H}_{2}$ to appear at $4153 \mathrm{~cm}^{-1}$. A comparison of Raman spectra and scanning probe microscopy results shows that hydrogenation forms defects (platelets) of average size $43 \mathrm{~nm}$ and surface density $6.5 \cdot 10^{9} \mathrm{~cm}^{-2}$ that are due to precipitation of $\mathrm{H}_{2}$ and formation of $\mathrm{Si}-\mathrm{H}$ bonds. Inclusions of average size $115 \mathrm{~nm}$ and surface density $1.7 \cdot 10^{9} \mathrm{~cm}^{-2}$ that are filled with molecular $\mathrm{H}_{2}$ are observed after heat treatment. The concentration of free charge carriers remains constant after treatment in plasma and subsequent heat treatment.

Keywords: epitaxial silicon, hydrogen plasma, Raman scattering, scanning probe microscope, Hall effect.

Introduction. Hydrogen $\left(\mathrm{H}_{2}\right)$ in silicon $(\mathrm{Si})$ is an important technological dopant that affects its optical and electrical properties [1]. $\mathrm{H}_{2}$ can passivate electrically active dopants and recombination impurities [1] or activate neutral ones such as oxygen, which enhances oxygen-related thermal donor (OTD) formation [2, 3], because of its high chemical reactivity and mobility. According to the literature [4], exposure to $\mathrm{H}_{2}$ plasma and subsequent heat treatment can lead to hydrogen thermal donor (HTD) formation. HTDs were reported to form after implantation of hydrogen ions in Si and SiGe solid solutions [5-8]. Passivation and formation of electrically active centers during exposure to $\mathrm{H}_{2}$ plasma was associated with structural defect (platelet) formation due to $\mathrm{H}_{2}$ precipitation during plasma exposure and $\mathrm{Si}-\mathrm{H}$ bond formation [9, 10]. Information about further development of structural defects initiated by hydrogen are contradictory. According to some researchers [10], further development starts at $\sim 600^{\circ} \mathrm{C}$. Conversely, a band at $3601 \mathrm{~cm}^{-1}$ in Raman spectra after plasma exposure at $\leq 150^{\circ} \mathrm{C}$ was assigned to vibrations of $\mathrm{H}_{2}$ located near a tetragonal site in the Si lattice [11, 12]. A band at $4157 \mathrm{~cm}^{-1}$ characteristic of gaseous $\mathrm{H}_{2}$ was observed at $>150^{\circ} \mathrm{C}$. These effects were explained by capture of diffusing $\mathrm{H}_{2}$ in platelets and gaseous $\mathrm{H}_{2}$ formation in them $[11,12]$.

The present work studied transformations of structural defects and $\mathrm{Si}-\mathrm{H}_{x}$ complexes formed in $\mathrm{Si}$ by exposure to $\mathrm{H}_{2}$ plasma and then heat treatment and their effects on the electrical and optical properties of hydrogenated Si.

Experimental. Epitaxial structures $n-\mathrm{Si} / p^{+}-\mathrm{Si}$ were exposed to $\mathrm{H}_{2}$ plasma in the work. The structures were grown in Si substrates $(<111>$ orientation, $510-540-\mu \mathrm{m}$ thick). The epitaxial layer $(55.2-64.8 \mu \mathrm{m})$ was doped with phosphorus $(\rho=1 \Omega \cdot \mathrm{cm})$. Structures were exposed to high-frequency $(13.5 \mathrm{MHz}, 50 \mathrm{~W}) \mathrm{H}_{2}$ plasma for up to $10 \mathrm{~h}$ at $150^{\circ} \mathrm{C}$.

Raman spectra were recorded at room temperature using a Nanofinder ${ }^{\circledR}$ HE micro-Raman spectrometer of $0.3 \mathrm{~cm}^{-1}$ resolution fitted with a back-scattering 3D-scanning confocal microscope. Power of $2 \mathrm{~mW}$ was directed at the sample. The exciting beam had a diameter of $\sim 1 \mu \mathrm{m}$. A solid-state laser with 532-nm radiation was used for excitation.

* To whom correspondence should be addressed.

${ }^{\mathrm{a}}$ Belarusian State University, 4 Nezavisimost' Ave., Minsk, 220030, Belarus; email: pokotilo@bsu.by; ${ }^{\mathrm{b}}$ Department of Electrical and Electronic Engineering, University of Manchester, M13 9PL, United Kingdom; email: V.Markevich@ manchester.ac.uk; ${ }^{\mathrm{c}}$ Al-Balqa Applied University, Salt, 19117, Jordan; email: anismhsaad@bau.edu.jo. Translated from Zhurnal Prikladnoi Spektroskopii, Vol. 86, No. 5, pp. 735-738, September-October, 2019. Original article submitted April 5, 2019. 
$I$, rel. units

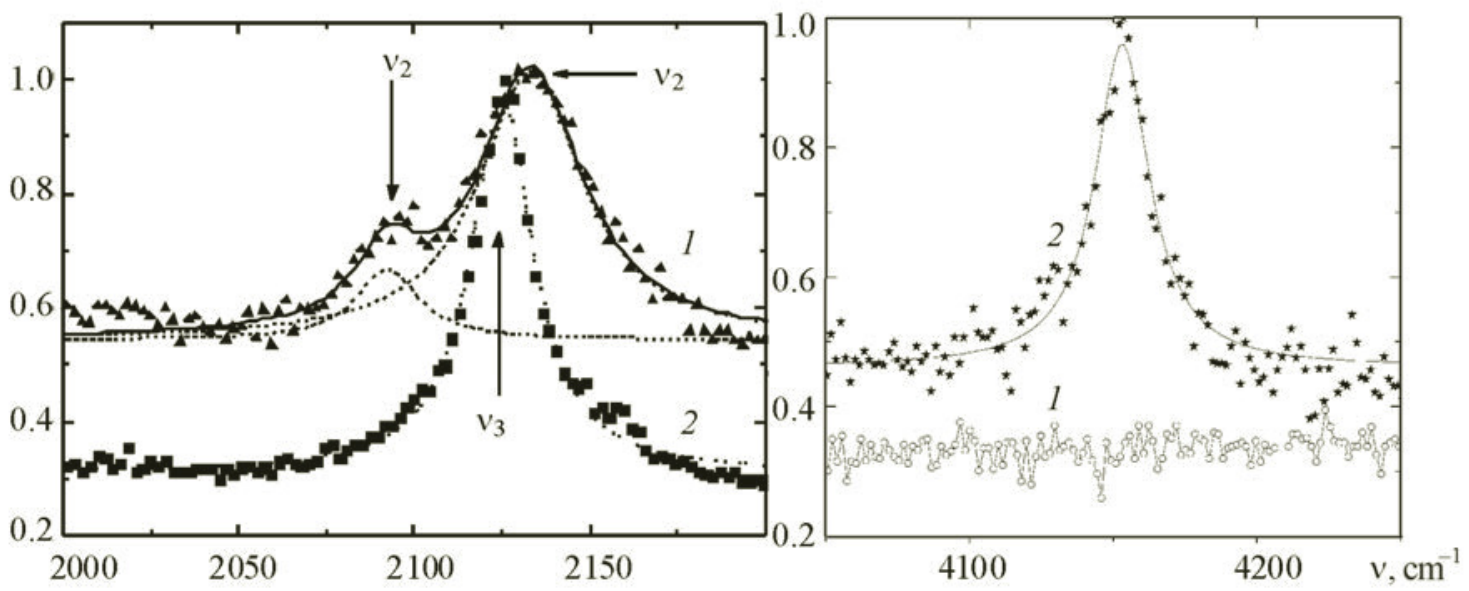

Fig. 1. Experimental Raman spectra in different frequency ranges of samples treated in $\mathrm{H}$ plasma (1) and subsequently annealed at $275^{\circ} \mathrm{C}$ for $20 \mathrm{~min}(2)$; dashed line, deconvolution of spectra into elementary Lorentzian oscillators.
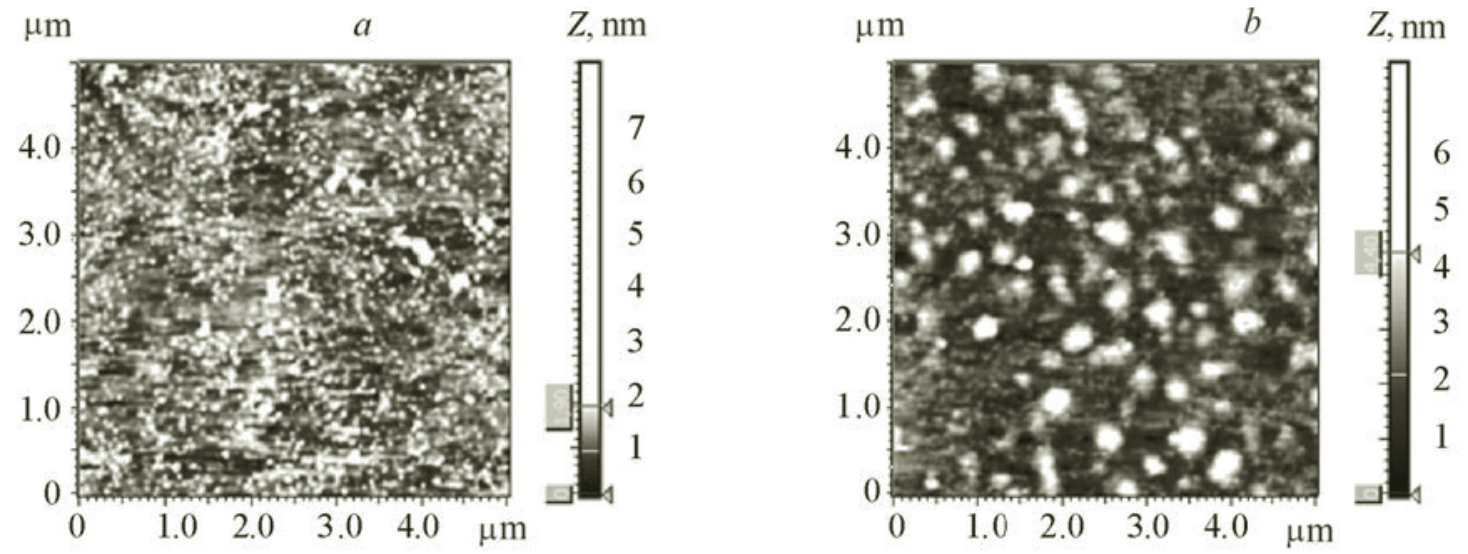

Fig. 2. Surface morphology of hydrogenated silicon before (a) and after (b) heat treatment at $275^{\circ} \mathrm{C}$ for $20 \mathrm{~min}$.

Resistance and the Hall effect were measured using an HEMS high field measurement system (Cryogenic Ltd., London) that allowed the sample temperature to be held at 2-300 K with $0.05 \mathrm{~K}$ accuracy. A Keithley 6430 source/meter and Keithley $2821 \mathrm{~A}$ nanovoltmeter were used as the source and meter of DC and potential.

Surface morphology was studied using a Solver nano scanning probe microscope (SPM) (NT-MDT) in semicontact mode.

Results and Discussion. Evolution of Raman spectra. Figure 1 shows Raman spectra of samples after exposure to $\mathrm{H}_{2}$ plasma and subsequent annealing at $275^{\circ} \mathrm{C}$ for $20 \mathrm{~min}$. Plasma exposure produced two overlapping bands with maxima at $2095\left(v_{2}\right)$ and $2129 \mathrm{~cm}^{-1}\left(v_{1}\right)$. These bands disappeared and a narrow band with a maximum at $2125 \mathrm{~cm}^{-1}\left(v_{3}\right)$ appeared after annealing at $275^{\circ} \mathrm{C}$ for $20 \mathrm{~min}$. The observed bands corresponded to various $\mathrm{Si}-\mathrm{H}$ vibrations $\left(\mathrm{Si}-\mathrm{H}_{x}\right.$, where $\left.x=1-4\right)$ localized on platelets $[10,12]$. Furthermore, subsequent heat treatment produced a new band at $4153 \mathrm{~cm}^{-1}$ in the Raman spectrum (Fig. 1b) that was reported to correspond to vibrations of isolated gaseous $\mathrm{H}_{2}[11,12]$.

Surface morphology. Sample surface morphologies were measured to establish the relationship between thermal evolution of hydrogen defects and transformation of structural defects. Figure 2a shows the surface morphology of Si after exposure to plasma. The surface was characterized by highly concentrated fine inhomogeneities. Computer processing found that 1618 inhomogeneities were detected in an arbitrarily selected $5 \times 5-\mu \mathrm{m}$ section of the sample (surface density 


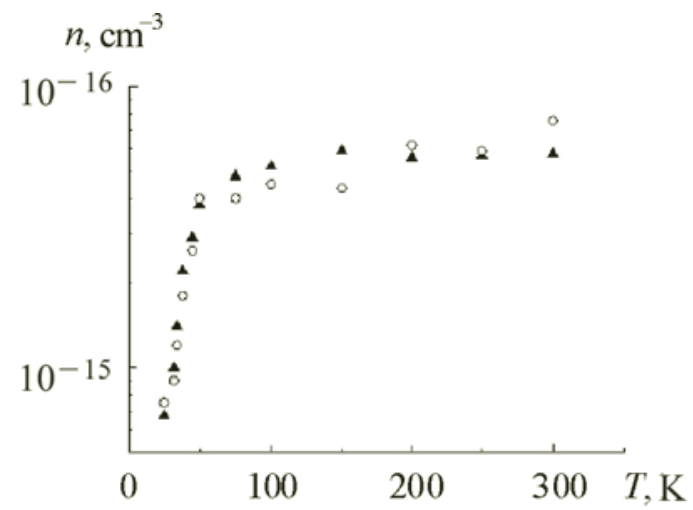

Fig. 3. Temperature dependences of charge carrier concentration in silicon samples after hydrogenation without $(\boldsymbol{\Delta})$ and with subsequent heat treatment (०).

$6.5 \cdot 10^{9} \mathrm{~cm}^{-2}$ ), the average size of which was $43 \mathrm{~nm}$. The surface roughness was $1.1 \mathrm{~nm}$. Heat treatment at $275^{\circ} \mathrm{C}$ changed considerably the surface morphology (Fig. 2b). The inhomogeneity diameter increased to an average of $115 \mathrm{~nm}$. The surface density decreased to $1.7 \cdot 10^{9} \mathrm{~cm}^{-2}$. The surface roughness about doubled.

The Raman and SPM results led to the conclusion that the inhomogeneities observed in Fig. 2a were platelets due to slippage of $\mathrm{Si}-\mathrm{H}_{x}$ bonds [7-9]; the inhomogeneities in Fig. 2b, vacancies filled with gaseous molecular $\mathrm{H}_{2}$.

Temperature dependences of electron concentrations. Figure 3 shows temperature dependences of electron concentration at 20-300 K from Hall-effect potentials for Si samples after exposure to plasma and subsequent heat treatment. Data analysis showed that the electron concentration of $\sim 6 \cdot 10^{15} \mathrm{~cm}^{-3}$ near an impurity-depleted region corresponded to the initial donor concentration. Therefore, hydrogenation and heat treatment of Si under these conditions did not passivate the impurities and form hydrogen donors.

Conclusions. A comparison of Raman spectra and SPM results showed that $\mathrm{Si}$ exposed to $\mathrm{H}_{2}$ plasma $\left(150^{\circ} \mathrm{C}\right)$ formed inhomogeneities (platelets) due to $\mathrm{H}_{2}$ precipitation and $\mathrm{Si}-\mathrm{H}_{x}$ (where $x=1-4$ ) bond formation. This was consistent with known Raman bands at $\sim 2000 \mathrm{~cm}^{-1}$. Addition heat treatment of the samples at $275^{\circ} \mathrm{C}$ formed platelets and larger inhomogeneities. A band at $4153 \mathrm{~cm}^{-1}$ for molecular $\mathrm{H}_{2}$ vibrations appeared in the Raman spectrum. Therefore, high-temperature annealing formed $\mathrm{Si}$ voids in the lattice that were filled with gaseous $\mathrm{H}_{2}$. Transformations of structural defects and hydrogen centers (aggregates of $\mathrm{Si}-\mathrm{H}_{x}$ complexes) did not affect the concentration of fundamental charge carriers.

Acknowledgment. We thank A. V. Mazanik for valuable comments and attention to the work.

\section{REFERENCES}

1. S. J. Pearton, J. W. Corbet, and S. Shi, Appl. Phys. A: Solids Surf., 43, 153-195 (1987).

2. H. J. Stein and S. K. Hahn, J. Appl. Phys., 75, 3477-3484 (1994).

3. V. P. Markevich, L. I. Murin, J. L. Lindstrom, and M. Suezava, Fiz. Tekh. Poluprovodn., 34, No. 9, 1039-1045 (2000).

4. E. Simoen, Y. L. Huang, Y. Ma, J. Lauwaert, P. Clauws, J. M. Rafí, A. Ulyashin, and C. Claeys, J. Electrochem. Soc., 156, No. 6, H434-H442 (2009).

5. Y. Ohmura, Y. Zohta, and M. Kanazava, Phys. Status Solidi A, 15, 93-98 (1973).

6. Yu. Gorelkinskii and N. N. Nevinnyi, Nucl. Instrum. Methods Phys. Res., 209/210, 677-682 (1983).

7. J. Hartung and J. Weber, Phys. Rev. B: Condens. Matter Mater. Phys., 48, 14161-14166 (1993).

8. V. P. Markevich, L. Dobaczewski, K. Bonde Niellsen, V. V. Litvinov, A. N. Petukh, Yu. M. Pokotilo, N. V. Abrosimov, and A. R. Peaker, Thin Solid Films, 517, 419-421 (2008).

9. Kh. A. Abdullin, Yu. V. Gorelkinskii, B. N. Mukashev, and S. Zh. Tokmoldin, Fiz. Tekh. Poluprovodn., 36, No. 3, 257-268 (2002).

10. H. Nordmark, A. G. Ulyashin, J. C. Walmsley, and R. Holmestad, J. Phys.: Conf. Ser., 281, 012029(1-13) (2011).

11. K. Murakami, N. Fukata, S. Sasaki, R. Ishioka, M. Kitajima, S. Fujimura, J. Kikuchi, and J. Haneda, Phys. Rev. Lett., 77, 3161-3164 (1996).

12. A. W. R. Leitch, J. Weber, and V. Alex, Mater. Sci. Eng. B, 58, 6-12 (1999). 